Original Research Paper

\title{
Optimization for the Extraction of Polysaccharide from Walnut (Juglans regia L.) Leaves: Antioxidant Activities in Vitro
}

\author{
Shuqing Yang, Haifang Xiao, Shuyan Yu, Zhike Xie, Shaoxuan Yu, Wanting Sun and Yuanda Song \\ Colin Ratledge Center for Microbial Lipids, School of Agricultural Engineering and Food Science, \\ Shandong University of Technology, Zibo, China
}

Article history

Received: 14-08-2019

Revised: 18-09-2019

Accepted: 18-10-2019

Corresponding Author:

Haifang Xiao

Colin Ratledge Center for

Microbial Lipids, School of

Agricultural Engineering and

Food Science,

Email: xiaohaifang@sdut.edu.cn

\begin{abstract}
Cellulase-assisted extraction of Walnut Leaf Polysaccharide (WLP) was studied. Single factor test and response surface design were employed to optimize the technological conditions. The consequences indicated that the highest WLP yield of 5.21\% was achieved with raw material ratio of $50 \mathrm{~mL} / \mathrm{g}$, cellulase dose of $41488.52 \mathrm{U} / \mathrm{g}$, enzymolysis $\mathrm{pH}$ of 5.88, enzymolysis time of $29.74 \mathrm{~min}$ and enzymolysis temperature of $52.07^{\circ} \mathrm{C}$. Moreover, in vitro antioxidant assays revealed that WLP has significant eliminating capability against 1, 1-diphenyl-2-picrylhydrazyl (DPPH), 2, 2'-azino-bis (3-ethylbenzothiazoline-6-sulfonic acid) (ABTS) and hydroxyl free radicals in a dose-dependent manner and exhibited a strong reducing power. These results suggest that WLP could be developed as a promising natural antioxidant agent in the pharmaceutical and functional food industries.
\end{abstract}

Keywords: Polysaccharide, Walnut Leaf, Antioxidant

\section{Introduction}

With the advancement of separation and identification technologies, the extraction of active substances from plants becomes the principal pathway to further utilize agricultural wastes (Jeddou et al., 2016). Walnut is a kind of economic crop planted widely in the world and its fruit has abundant functional activities (Carvalho et al., 2010). Nevertheless, there are few studies on walnut leaves at present, which results in a huge waste of resources. For a long time, walnut leaves have been used not only in the production of tea but also in traditional medicine for the treatment of various diseases (Almeida et al., 2008; Forino et al., 2016; Pereira et al., 2007). In addition, reports indicate that walnut leaves have anti-diabetes and anti-inflammatory effects (Forino, et al., 2016; Mollica et al., Bellagamba, et al., 2017). Therefore, the development of walnut leaves is conducive to maximize resource utilization.

It is universally knowledge that free radicals can cause degenerative diseases, such as cancer, atherosclerosis, neurodegenerative diseases, aging, diabetes and immune system decline (Gao et al., 2015; Lai et al., 2010). Therefore, antioxidant substances play an important role in cleaning up excessive free radicals and maintaining human health (Kurd and Samavati, 2015). Plant polysaccharides are good sources of antioxidants. According to the report, three purified polysaccharides extracted from chuanxiong rhizome, LCX0, LCX1 and LCX2, exhibited strong antioxidant activities (Hu et al., 2016). Potatoe peel polysaccharide and arthrocnemum indicum leaf polysaccharide exhibited fairly strong cleaning capacities on DPPH and ABTS radicals in vitro (Jeddou et al., 2016; Mzoughi et al., 2018). What's more, cordyceps sinensis polysaccharide restrained PDGF-BB-induced ROS generation through ERK/Akt pathway (Yu et al., 2018). Judging from these, the antioxidant function of polysaccharides has received extensive attention. However, the antioxidant capability of polysaccharides from walnut leaves has not been investigated.

Compared with traditional hot water extraction, enzyme-assisted extraction which has become an alternative method to extract natural products is more environmental-friendly, efficient and easier to operate (Zhu et al., 2014). Cellulase is a complex enzyme system consisting of a variety of hydrolytic enzymes which generally exist in organisms. It can effectively destroy the cell wall structure and facilitate the release of intracellular biological active components (Yang et al., 2017). Therefore, cellulase has significant application value in the process of polysaccharide extraction. Response Surface Methodology (RSM) is a statistical 
method to optimize complex processes by evaluating the interaction between various factors to find the optimal process parameters (Kurd and Samavati, 2015; Mzoughi et al., 2018). Because of its high efficiency, RSM has been widely used by researchers to optimize the extraction process of bioactive substances (Xu et al., 2016; Yin et al., 2018). So far, there has been no report about enzyme-assisted extraction of polysaccharide from walnut leaves using RSM.

Base on the above, this study reported the optimum extraction process of WLP assisted by cellulase and investigated its antioxidant activities through DPPH, ABTS, hydroxyl radical scavenging capacities and Ferric Reducing/Antioxidant Power (FRAP) assay. Our work will help to further understand the functional activities of walnut leaves and provide a basis for the development and utilization of walnut leaves in the future.

\section{Materials and Methods}

\section{Materials}

Fresh leaves of walnut were gathered from Zibo city, North of Shangdong, in July 2018. The leaves were shade dried and ground into fine powder. Then, the resulting pulverescent samples were stored in a desiccator for future use.

Cellulase was purchased from Beijing Solarbio Science and Technology Co., Ltd (Beijing, China). Ascorbic acid was purchased from Tianjin Fuchen Chemical Reagent Co., Ltd (Tianjin, China). DPPH and ABTS were purchased from Shanghai yuanye BioTechnology Co., Ltd (Shanghai, China). All other reagents were analytical grade. Ultrapure water was prepared for the experiment.

DZK thermostatic electric oscillating water bath (Shanghai Yiheng Scientific Instrument Co., Ltd.); FW100 high speed pulverizer (Tianjin Tester Instrument Co., Ltd.); RE-52AA rotary evaporators (Shanghai Yarong Biochemical Instrument Factory); 5810R supercentrifuge (German Eppendorf Vo., LTD); UV2600 ultraviolet spectrophotometer (Shimadu Co., Ltd.).

\section{Methods}

\section{Single-Factor Experimental Design of Polysaccharide Extraction}

The single-factor design was employed to analyze the effects of extraction variables on polysaccharide extraction. Prepared samples (5 g) were churned in the cellulase-added ultrapure water according to a certain proportion (the cellulase dosage ranging from $1 \times 10^{4}$ to $5 \times 10^{4} \mathrm{U} / \mathrm{g}$; liquid-material ratio ranging from 20 to $60 \mathrm{~mL} / \mathrm{g}$ ) and then the prescriptive enzymolysis $\mathrm{pH}$ (4-7) value was adjusted. Throughout the course of extraction, the beaker was placed in a vibrating water bath at a given enzymolysis temperature $\left(30-70^{\circ} \mathrm{C}\right)$ for a certain period of time (10-60 min). Each experiment was performed in triplicate.

Following extraction, the solution was collected by centrifugation (4000 rpm, $10 \mathrm{~min}$ ) and evaporated using rotary evaporator at $60^{\circ} \mathrm{C}$ under vacuum. Sevage method was used to remove the free proteins in concentrated solutions. Ethanol was added to a final concentration of $95 \%(\mathrm{v} / \mathrm{v})$ and kept at $4^{\circ} \mathrm{C}$ for $12 \mathrm{~h}$. The precipitate was obtained by centrifugation (4000 r/min, $10 \mathrm{~min})$ and then lyophilized to obtain WLP (Yun et al., 2019). The polysaccharide content was measured using the phenolsulfuric method. Extraction yield of the polysaccharide weight (Equation 1):

$$
Y(\%, w / w)=W_{0} / W \times 100
$$

$W_{0}(g)$ is the weight of WLP; $W(g)$ is the weight of pretreated powder of walnut leaves.

\section{Box-Behnken Design (BBD) for Extraction Optimization}

On the basis of the single-factor experiment, a threelevel four-factor BBD was used to determine optimal levels of extraction variables including the cellulase dosage $\left(\mathrm{U} / \mathrm{g}, \mathrm{X}_{1}\right)$, enzymolysis $\mathrm{pH}\left(\mathrm{X}_{2}\right)$, enzymolysis time (min, $\left.\mathrm{X}_{3}\right)$, enzymolysis temperature $\left({ }^{\circ} \mathrm{C}, \mathrm{X}_{4}\right)$ for the extraction yield of WLP (Wu et al., 2014). The coded and uncoded levels of independent variables were shown in Table 1 and 29 experimental runs in random order were required. The general form of the quadratic regression model was expressed as the following Equation 2 (Yin et al., 2018):

$$
Y=\beta_{0}+\sum_{i=1}^{4} \beta_{i} X_{i}+\sum_{i=1}^{4} \beta_{i i} X_{i}^{2}+\sum_{i<j=2}^{4} \beta_{i j} X_{i} X_{j}
$$

Where:

$Y \quad=$ The predicted WLP extraction ratio

$\beta_{0} \quad=$ The constant term

$\beta_{i}, \beta_{i \mathrm{i}}$ and $\beta_{i j}=$ The regression coefficients for linear, quadratic and interactive terms, respectively

$X_{i}$ and $X_{j} \quad=$ The coded independent variables

\section{DPPH Free Radical Scavenging Assay}

DPPH method was proposed in 1958 and widely used for quantitative determination of antioxidant capacity of biological samples and food. The scavenging power on DPPH free radical of WLP was investigated according to previous method with slight modifications (Gao et al., 2015). In short, polysaccharide solutions of different concentrations were prepared. Two milliliter of sample solution with variable concentrations $(0.05-0.8 \mathrm{mg} / \mathrm{mL})$ was mixed with $2 \mathrm{~mL}$ of DPPH in $95 \%$ ethanol $(0.1 \mathrm{mM})$. 
Table 1: Factors and coding value of response surface experimental designment

\begin{tabular}{lllll}
\hline Levels & $\begin{array}{l}\text { Cellulase } \\
\text { dosage }\left(\mathrm{X}_{1}\right) / \mathrm{U} / \mathrm{g}\end{array}$ & $\begin{array}{l}\text { Enzymolysis } \\
\mathrm{pH}\left(\mathrm{X}_{2}\right)\end{array}$ & $\begin{array}{l}\text { Enzymolysis } \\
\text { time }\left(\mathrm{X}_{3}\right) / \mathrm{min}\end{array}$ & $\begin{array}{l}\text { Enzymolysis } \\
\text { temperature }\left(\mathrm{X}_{4}\right) /{ }^{\circ} \mathrm{C}\end{array}$ \\
\hline-1 & $3 \times 10^{4}$ & 5 & 20 & 40 \\
0 & $4 \times 10^{4}$ & 6 & 30 & 50 \\
1 & $5 \times 10^{4}$ & 7 & 40 & 6 \\
\hline
\end{tabular}

The reaction mixture was incubated at room temperature for $30 \mathrm{~min}$ in the dark. The absorbance was measured against a blank at $517 \mathrm{~nm}$. Ascorbic acid was used as the positive control. The DPPH radical scavenging ratio of WLP was calculated according to the following equation (Equation 3):

$$
D P P F \text { radical scavenging ability }(\%)=\left(1-\frac{A_{1}-A_{2}}{A_{3}}\right) \times 100
$$

where, $A_{1}$ is the absorbance of the various test samples, $A_{2}$ refers to the absorbance of the sample without the DPPH solution, $A_{3}$ is the absorbance of the control (ethanol instead of sample). Tests were executed in triplicate.

\section{ABTS Free Radical Scavenging Assay}

The ABTS free radical scavenging capacity of WLP was performed based on a modified edition of method reported by Wang et al. (2015). Briefly, the ABTS radical solution was obtained through $10 \mathrm{~mL}$ of $7 \mathrm{mM}$ ABTS solution was mixed with $10 \mathrm{~mL}$ of $2.45 \mathrm{mM}$ potassium persulfate. After blending, the mixture was preserved in the dark at room temperature for $12 \mathrm{~h}$. Then the solution was diluted with distilled water to an absorbance of $0.7 \pm 0.02$ at $734 \mathrm{~nm}$ before used.

To estimate the depolarization activity, $2 \mathrm{~mL}$ different concentrations of polysaccharide samples $(0.05-0.8 \mathrm{mg} / \mathrm{mL})$ was mixed with $2 \mathrm{~mL}$ of the diluted ABTS reagent. The blend was allowed to react at room temperature for $1 \mathrm{~h}$ and the absorbance was measured at $734 \mathrm{~nm}$. Ascorbic acid was used as the positive control. The scavenging activity of ABTS radicals was calculated using the following formula (Equation 4):

$$
\text { ABTS radical scavenging ability }(\%)=\left(1-\frac{A_{1}}{A_{2}}\right) \times 100
$$

Where:

$A_{1}=$ The absorbance of the diluted ABTS solution plus samples at different concentrations and

$A_{2}=$ The absorbance of distilled water mixed with $A B T S$

\section{FRAP Assay}

The FRAP of WLP was assayed according to the literature reported by $\mathrm{Wu}$ et al. with some modifications (Wu et al., 2014). In brief, the working solution contained $2.5 \mathrm{~mL}$ polysaccharide samples of various concentrations (0.4-6.4 mg/mL), $2.5 \mathrm{~mL}$ phosphate buffer (0.2 M, pH 6.6) and $2.5 \mathrm{~mL}$ potassium ferricyanide $(1 \%$, w/v). After hatched in a water bath at $50^{\circ} \mathrm{C}$ for $20 \mathrm{~min}, 2.5 \mathrm{~mL}$ of trichloroacetic acid $(10 \%, \mathrm{w} / \mathrm{v})$ was appended to the working solution to terminate the reaction. The mixture was then centrifuged ( $3500 \mathrm{r} / \mathrm{min})$ for $10 \mathrm{~min}$. Thereafter, $2.5 \mathrm{~mL}$ of the supernatant was mixed with $0.5 \mathrm{~mL}$ of deionized water and $0.5 \mathrm{~mL}$ of $\mathrm{FeCl}_{3}(0.1 \%$, w/v). After allowing the reaction to continue for $15 \mathrm{~min}$ at room temperature, the absorbance of the samples and ascorbic acid were measured at $700 \mathrm{~nm}$. A higher absorbance manifested a greater reducing capability. Values presented are the mean of triplicate analyses.

\section{Hydroxyl Radical Scavenging Assay}

Method reported by Yin et al. was used to investigate hydroxyl radical scavenging activity of WLP with some changes (Yin et al., 2018). Samples of various concentrations $(2-10 \mathrm{mg} / \mathrm{mL})$ were mixed with $1 \mathrm{~mL}$ of $\mathrm{FeSO}_{4}(10 \mathrm{mM}), 1 \mathrm{~mL}$ of salicylic acid-ethanol $(10 \mathrm{mM})$ and $0.5 \mathrm{~mL} \mathrm{H}_{2} \mathrm{O}_{2}(10 \mathrm{mM})$. The final mixture was kept for $30 \mathrm{~min}$ at $37^{\circ} \mathrm{C}$ and the absorbance at $510 \mathrm{~nm}$ was recorded. The following formula was used (Equation 5):

$$
\text { Hydroxyl radicalsscavenging rate }(\%)=\left(1-\frac{A_{1}-A_{2}}{A_{3}}\right) \times 100
$$

Where:

$A_{1}=$ The absorbance of the mixture with sample solution

$A_{2}=$ The absorbance of the $\mathrm{H}_{2} \mathrm{O}_{2}$ replaced by distilled water

$A_{3}=$ The absorbance of the blank reaction (distilled water instead of the sample)

\section{Statistical Analysis}

The experimental design and statistically analysis of the results of RSM were executed by DesignExpert Version software (version 8.0.6.1, State-Ease, Inc., Minneapolis, MN, USA). All data were indicated as the means \pm Standard Deviation (SD) and evaluated using Analysis Of Variance (ANOVA). For all comparisons, a significant difference was judged to be statistically significant if $P<0.05$.

\section{Results and Discussion}

\section{Effect of Cellulase Dosage on Extraction Yield}

Cellulase is used to hydrolyze or degrade the cell walls of plants to improve the extraction rate. The cellulase amounts can markedly affect the yield of the effective constituent in the enzyme-assisted 
extraction. As a consequence, different cellulase dosages $\left(1,2,3,4\right.$ and $\left.5 \times 10^{4} \mathrm{U} / \mathrm{g}\right)$ were investigated with enzymolysis $\mathrm{pH}$ of 6 , enzymolysis time of 30 min, liquid-material ratio of $30 \mathrm{~mL} / \mathrm{g}$ and enzymolysis temperature of $50^{\circ} \mathrm{C}$. As shown in Fig. 1, the extraction rate of WLP increased from $1.52 \%$ to
$4.57 \%$ and then fall slowly as the cellulase dosage increased from $1 \times 10^{4}$ to $5 \times 10^{4} \mathrm{U} / \mathrm{g}$, which was consistent with the results in previous studies (Yin et al., 2016). Possible reason for this phenomenon is that WLP glucosidic bonds is partially hydrolyzed on account of the saturated substrate.

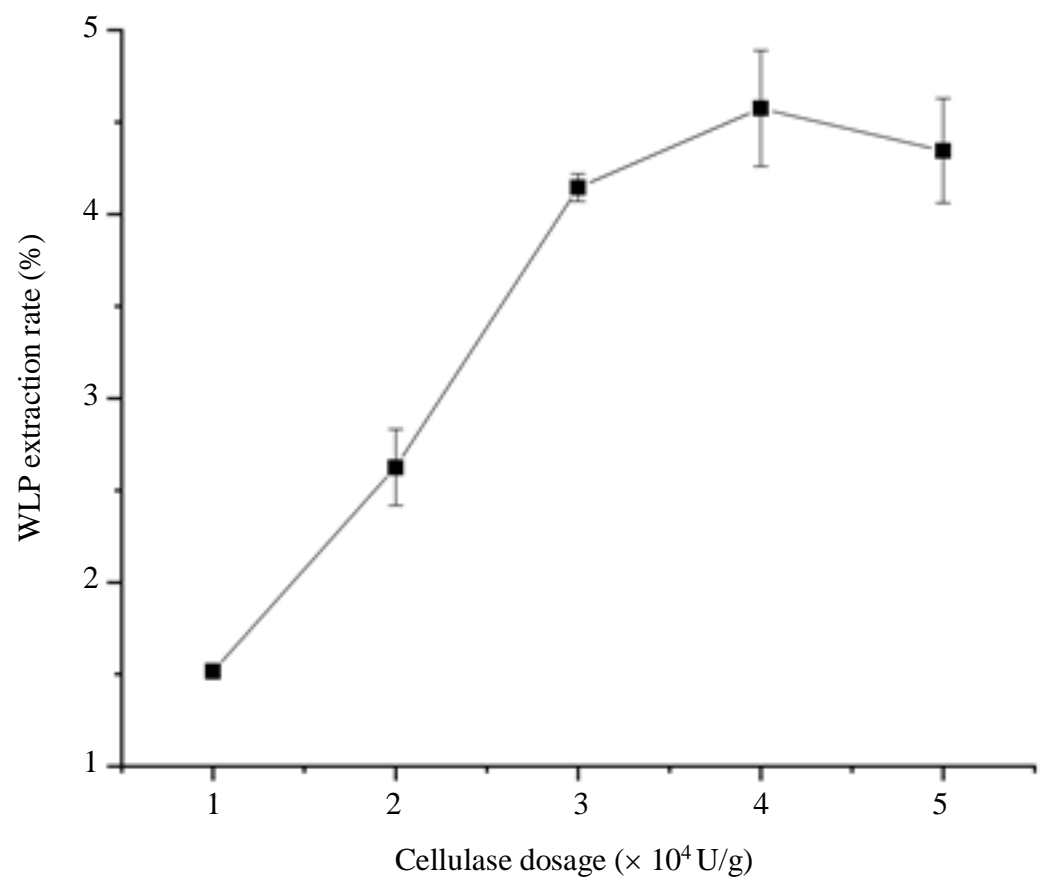

Fig. 1: Effects of cellulase dosage on extraction yield of WLP. Each value represents the mean \pm SD of three determinations

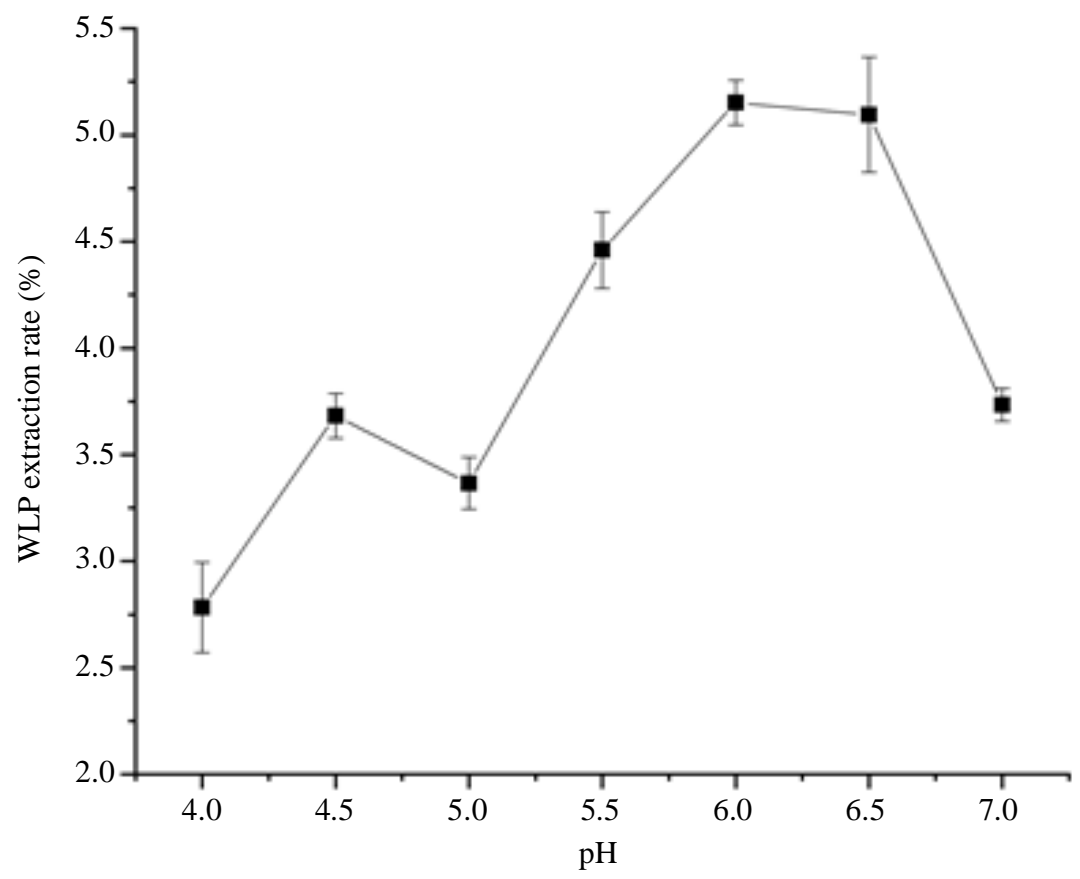

Fig. 2: Effects of enzymolysis $\mathrm{pH}$ on extraction yield of WLP. Each value represents the mean \pm SD of three determinations 


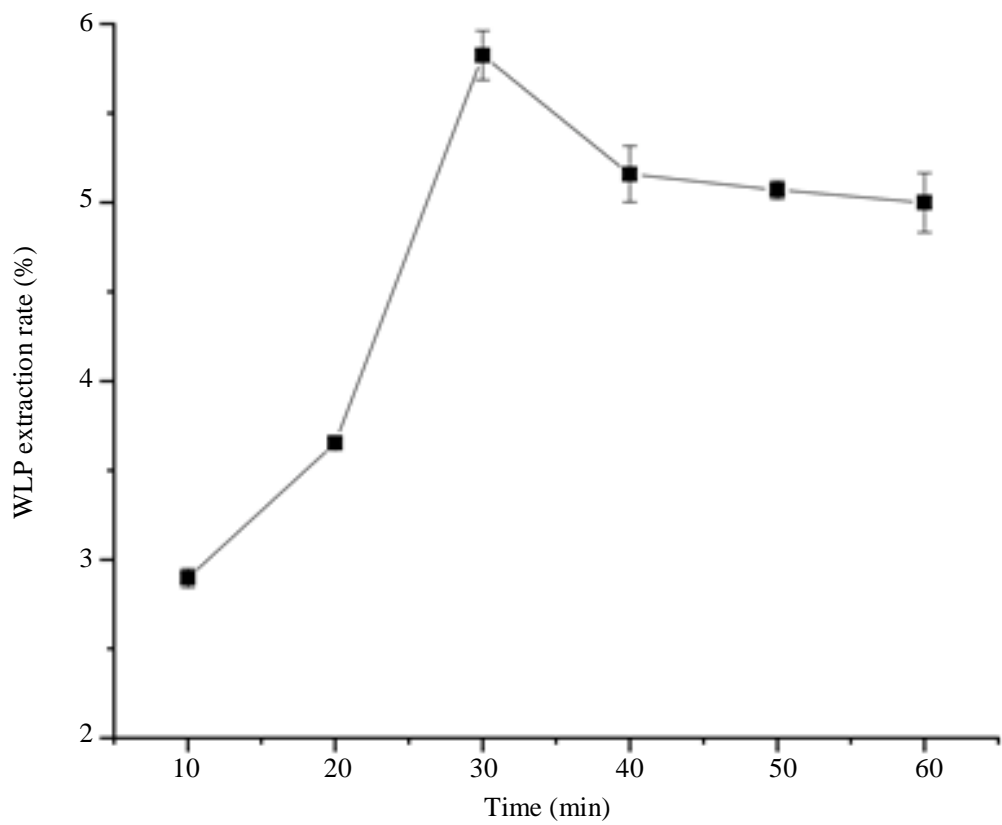

Fig. 3: Effects of enzymolysis time on extraction yield of WLP. Each value represents the mean \pm SD of three determinations

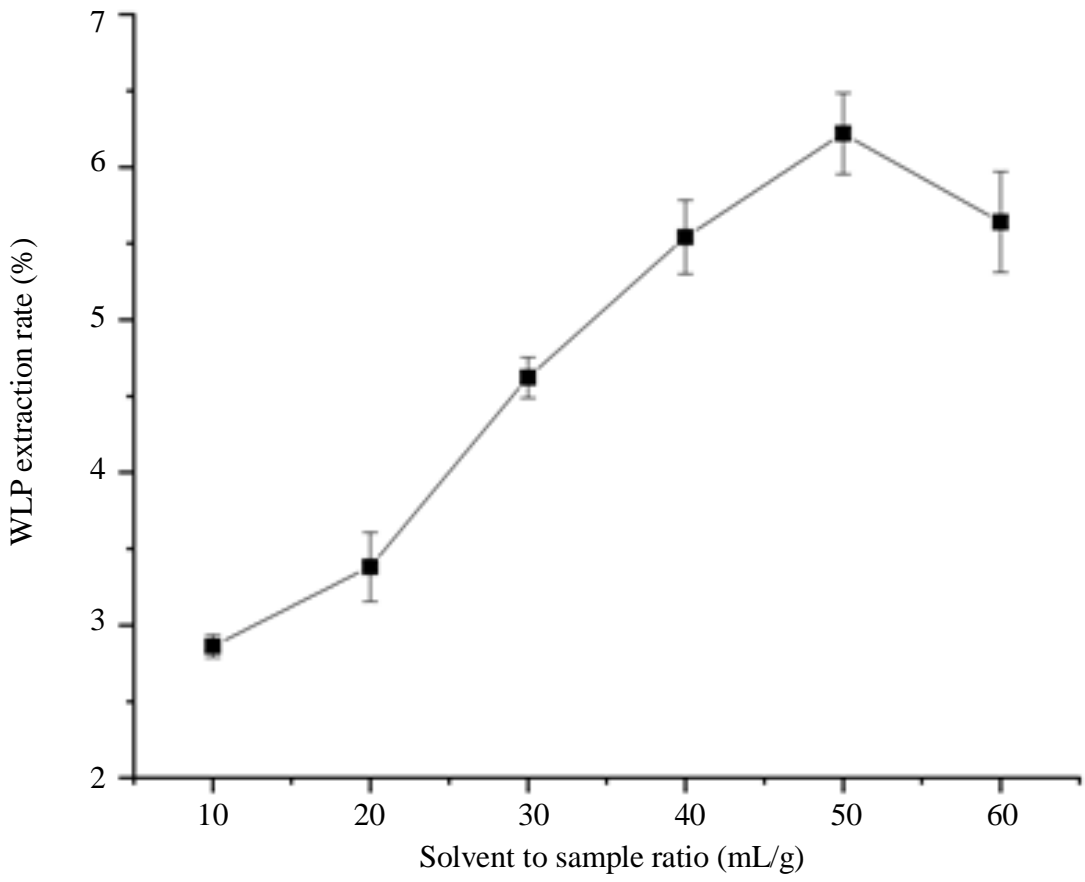

Fig. 4: Effects of solvent to sample ratio on extraction yield of WLP. Each value represents the mean \pm SD of three determinations

\section{Effect of Enzymolysis pH on Extraction Yield}

In the process of enzymatic reaction, the extracting amount of target constituents can be maximized by different enzymes at the optimum $\mathrm{pH}$ value. Extraction technology was performed using various $\mathrm{pH}$ range from 4 to 7 and other variables such as cellulase dosage, liquid-material ratio, enzymolysis time and enzymolysis temperature were fixed at $4 \times 10^{4}$ $\mathrm{U} / \mathrm{g}, 30 \mathrm{~mL} / \mathrm{g}, 30 \mathrm{~min}$ and $50^{\circ} \mathrm{C}$, respectively. As can be seen in Fig. 2, the extraction rate of WLP gradually increased and then declined with the increase of $\mathrm{pH}$ value of the sample solution and the yield reached its maximum $(5.15 \%)$ at $\mathrm{pH}$. The interpretation for the 
result above is that the steric configuration of the cellulase may change under different acid and base conditions and then alters the enzyme conformation and vitality (Yin et al., 2018).

\section{Effect of Enzymolysis Time on Extraction Yield}

The effect of enzymolysis time on the extraction yield of WLP at a settled condition including the enzymolysis temperature of $50^{\circ} \mathrm{C}$, enzymolysis $\mathrm{pH}$ of 6 , liquid-material ratio of $30 \mathrm{~mL} / \mathrm{g}$ and cellulase dosage of $4 \times 10^{4} \mathrm{U} / \mathrm{g}$ was illustrated in Fig. 3, According to the results, the output of WLP was the highest $(5.82 \%)$ at the time of $30 \mathrm{~min}$, after more than $30 \mathrm{~min}$, the WLP yield showed a slight decline trend. This tendency of results was also in keeping with Yin et al.' s inquiry (Yin et al., 2018). The appearance of this phenomenon may be due to the long enzymolysis time leading to degradation of polysaccharides (Chen et al., 2017). We will discuss this issue through further experiments.

\section{Effect of Liquid-Material Ratio on Extraction Yield}

Extraction yield of bioactive compounds was significantly affected by the ratio of solvent to raw material. The polysaccharides in the raw materials will not be fully extracted with the small ratio of liquid to solid. However, too large ratio of liquid to material will lead to increased processing expenses (Kurd and Samavati, 2015). As shown in Fig. 4, a favorable impact was presented when the liquid-material ratio ranged from 10 to $50 \mathrm{~mL} / \mathrm{g}$. After the maximal output $(6.21 \%)$ was obtained, the extraction yield of WLP declined by degrees with the ulteriorly increase of liquid-material ratio. These results above might be attribute to the increased driving force of mass transfer with the increase of liquid-material ratio, which was beneficial to the desorption of WLP from the cells (Yang et al., 2017). Nevertheless, potentially on account of the oversaturation of WLP in water, the productive rate inclined to decline as the liquid- material ratio continued to rised, which is consistent with the previous report by (Yun et al., 2019).

\section{Effect of Enzymolysis Temperature on Extraction Yield}

The temperature of enzymatic hydrolysis exerts a significant effect on enzyme activity. Moreover, proper heat treatment plays an important role in extraction efficiency and quality loss (Yang et al., 2017). In this study, several temperatures including 30, 40, 50, 60 and $70^{\circ} \mathrm{C}$ were used and the cellulase dosage, enzymolysis $\mathrm{pH}$, enzymolysis time and liquid-material ratio were fixed at $4 \times 10^{4} \mathrm{U} / \mathrm{g}, 6,30 \mathrm{~min}$ and $50 \mathrm{~mL} / \mathrm{g}$, respectively. As shown in Fig. 5, with the rising temperature from 30 to $50^{\circ} \mathrm{C}$, the extraction yield of WLP increased gradually to a maximum of $4.21 \%$ and then decreased with the further increase of enzymolysis temperature. These results were consistent with what has been described in previous studies and might be attributed to the optimum hydrolytic activity of enzymes at the preferred temperature and lower hydrolytic activity of enzymes at other temperatures (Kurd and Samavati, 2015; Mazarei et al., 2017). on the other side, higher temperature can accelerate the motion of molecules which improve the electrical conductivity of the solvent to the raw material. The reaction mentioned above enhances the dissolvability and diffusion rate of the materials, thus further increase the extraction rate (Kurd and Samavati, 2015).

\section{Optimization of the Extraction Process by RSM}

\section{Models fitting and Statistical Analysis}

According to the results of single-factor experiments, we found that cellulase dosage, enzymolysis $\mathrm{pH}$, enzymolysis time and enzymolysis temperature played an important role in the extraction field of WLP. Thus, the extraction technology was further optimized by means of a three level and fourfactor RSM employing BBD method. The design matrix and the corresponding results of the WLP yield were listed in Table 2. A variety of multiple regression analysis was used to process the experiment data. The relationship between the response for extraction yield of WLP and the test variables were indicated in terms of following second-order polynomial equations (Equation 6):

$$
\begin{aligned}
& Y=5.13+0.24 X_{1}-0.43 X_{2}+0.003703 X_{3}+0.43 X_{4}+0.27 X_{1} X_{2} \\
& +0.038 X_{1} X_{3}+0.10 X_{1} X_{4}+0.42 X_{2} X_{3}+0.66 X_{2} X_{4}-0.18 X_{3} X_{4} \\
& -0.78 X_{1}^{2}-2.04 X_{2}^{2}-0.6 X_{3}^{3}-0.89 X_{4}^{2}
\end{aligned}
$$

where, $Y$ is the yield of WLP, $X_{1}, X_{2}, X_{3}$ and $X_{4}$ are the coded variables for the cellulase dosage, enzymolysis $\mathrm{pH}$, enzymolysis time, enzymolysis temperature, respectively.

The quadratic model based on multivariate regression analysis can fully describe the obtained data by evaluating the experimental data. The significance of parameters and the interaction of each coefficient were checked by F-test and P-value. Meanwhile, the precision and validity of the model were evaluated by the values of determination coefficient $\left(\mathrm{R}^{2}\right)$ and adjusted determination coefficient $\left(\mathrm{R}^{2}\right.$ adj) (Zhao et al., 2016). Table 3 listed the variance analysis (ANOVA) for the response surface quadratic model of WLP extraction. According to analysis of the model, the high-level $F$ value $(15.66)$ and low-grade $P$-value $(<0.0001)$ implied that the model was sky-high statistically significance (Chen et al., 2017). The lack of fit (F-values of 2.83 and p-value of 0.1641$)$ of the model was insignificant ( $p>$ $0.05)$ relative to the pure error. Furthermore, the high degree of correlation between the observed values was 
confirmed by the close proximity of the value of the determination coefficient $\left(R^{2}=0.94\right)$ and the adjusted coefficient of determination $\left(\mathrm{R}^{2}{ }_{a d j}=0.8799\right)$, which also recommended the reasonable and availability of the model (Kurd and Samavati, 2015). Base on the above, the regression model was reasonable.

Table 2: Box-behnken experimental design and results for extraction yield of WLP

\begin{tabular}{|c|c|c|c|c|c|}
\hline Runs & $\mathrm{X}_{1}(\mathrm{U} / \mathrm{g})$ & $\mathrm{X}_{2}$ & $\mathrm{X}_{3}(\min )$ & $\mathrm{X}_{4}\left({ }^{\circ} \mathrm{C}\right)$ & $\mathrm{Y}(\%)$ \\
\hline 1 & -1 & 0 & -1 & 0 & 3.77 \\
\hline 2 & 0 & 0 & 0 & 0 & 4.93 \\
\hline 3 & 0 & 1 & 1 & 0 & 3.41 \\
\hline 4 & 0 & 1 & 0 & 1 & 3.49 \\
\hline 5 & 1 & 0 & 1 & 0 & 3.75 \\
\hline 6 & 0 & -1 & 1 & 0 & 3.69 \\
\hline 7 & 0 & 0 & 0 & 0 & 5.09 \\
\hline 8 & 0 & 0 & 0 & 0 & 5.37 \\
\hline 9 & -1 & 1 & 0 & 0 & 2.29 \\
\hline 10 & -1 & 0 & 1 & 0 & 3.33 \\
\hline 11 & 0 & 0 & -1 & -1 & 2.68 \\
\hline 12 & 0 & 0 & 0 & 0 & 4.96 \\
\hline 13 & 0 & 0 & -1 & 1 & 4.26 \\
\hline 14 & 1 & -1 & 0 & 0 & 3.74 \\
\hline 15 & 0 & -1 & 0 & 1 & 3.62 \\
\hline 16 & 1 & 0 & 0 & 1 & 4.14 \\
\hline 17 & 0 & 0 & 1 & -1 & 3.21 \\
\hline 18 & -1 & -1 & 0 & 0 & 3.59 \\
\hline 19 & -1 & 0 & 0 & 1 & 3.49 \\
\hline 20 & 0 & 1 & -1 & 0 & 3.12 \\
\hline 21 & -1 & 0 & 0 & -1 & 3.01 \\
\hline 22 & 0 & 1 & 0 & -1 & 1.51 \\
\hline 23 & 1 & 0 & -1 & 0 & 4.04 \\
\hline 24 & 1 & 1 & 0 & 0 & 3.52 \\
\hline 25 & 0 & 0 & 0 & 0 & 5.29 \\
\hline 26 & 0 & -1 & -1 & 0 & 3.56 \\
\hline 27 & 0 & -1 & 0 & -1 & 4.29 \\
\hline 28 & 0 & 0 & 1 & 1 & 4.08 \\
\hline 29 & 1 & 0 & 0 & -1 & 3.23 \\
\hline
\end{tabular}

Table 3: Analysis of the variance (ANOVA) for the second-order polynomial model

\begin{tabular}{llllll}
\hline Source & Sum of squares & $\mathrm{df}$ & Mean square & F value & P value \\
\hline Model & 19.65 & 14 & 1.40 & 15.66 & $<0.0001^{\mathrm{a}}$ \\
$\mathrm{X}_{1}$ & 0.71 & 1 & 0.71 & 7.97 & $0.0136^{\mathrm{b}}$ \\
$\mathrm{X}_{2}$ & 2.21 & 1 & 2.21 & 24.60 & $0.0002^{\mathrm{a}}$ \\
$\mathrm{X}_{3}$ & $1.646 \times 10^{-4}$ & 1 & $1.646 \times 10^{-4}$ & $1.836 \times 10^{-3}$ & $0.9664^{\mathrm{c}}$ \\
$\mathrm{X}_{4}$ & 2.20 & 1 & 2.20 & 24.59 & $0.0002^{\mathrm{a}}$ \\
$\mathrm{X}_{1} \mathrm{X}_{2}$ & 0.30 & 1 & 0.30 & 3.30 & $0.0909^{\mathrm{c}}$ \\
$\mathrm{X}_{1} \mathrm{X}_{3}$ & $5.765 \times 10^{-3}$ & 1 & $5.765 \times 10^{-3}$ & 0.064 & $0.8035^{\mathrm{c}}$ \\
$\mathrm{X}_{1} \mathrm{X}_{4}$ & 0.044 & 1 & 0.044 & 0.49 & $0.4960^{\mathrm{c}}$ \\
$\mathrm{X}_{2} \mathrm{X}_{3}$ & $6.944 \times 10^{-3}$ & 1 & $6.944 \times 10^{-3}$ & 0.077 & $0.7848^{\mathrm{c}}$ \\
$\mathrm{X}_{2} \mathrm{X}_{4}$ & 1.76 & 1 & 1.76 & 19.59 & $0.0006^{\mathrm{a}}$ \\
$\mathrm{X}_{3} \mathrm{X}_{4}$ & 0.13 & 1 & 0.13 & 1.41 & $0.2548^{\mathrm{c}}$ \\
$\mathrm{X}_{1}{ }^{2}$ & 3.92 & 1 & 3.92 & 73.68 & $<0.0001^{\mathrm{a}}$ \\
$\mathrm{X}_{2}{ }^{2}$ & 6.97 & 1 & 6.97 & 30.73 & $<0.0001^{\mathrm{a}}$ \\
$\mathrm{X}_{3}{ }^{2}$ & 2.75 & 1 & 2.75 & 57.24 & $<0.0001^{\mathrm{a}}$ \\
$\mathrm{X}_{4}{ }^{2}$ & 5.13 & 1 & 5.13 & & $<0.0001^{\mathrm{a}}$ \\
Residual & 1.25 & 14 & 0.09 & 2.83 & $0.1641^{\mathrm{b}}$ \\
Lack of fit & 1.10 & 10 & 0.11 & & \\
Pure error & 0.16 & 4 & 0.039 & & \\
Cor total & 20.90 & 28 & & & \\
\hline
\end{tabular}

${ }^{\mathrm{a}} P<0.01$.

${ }^{\mathrm{b}} p<0.05$.

cNot significant. 


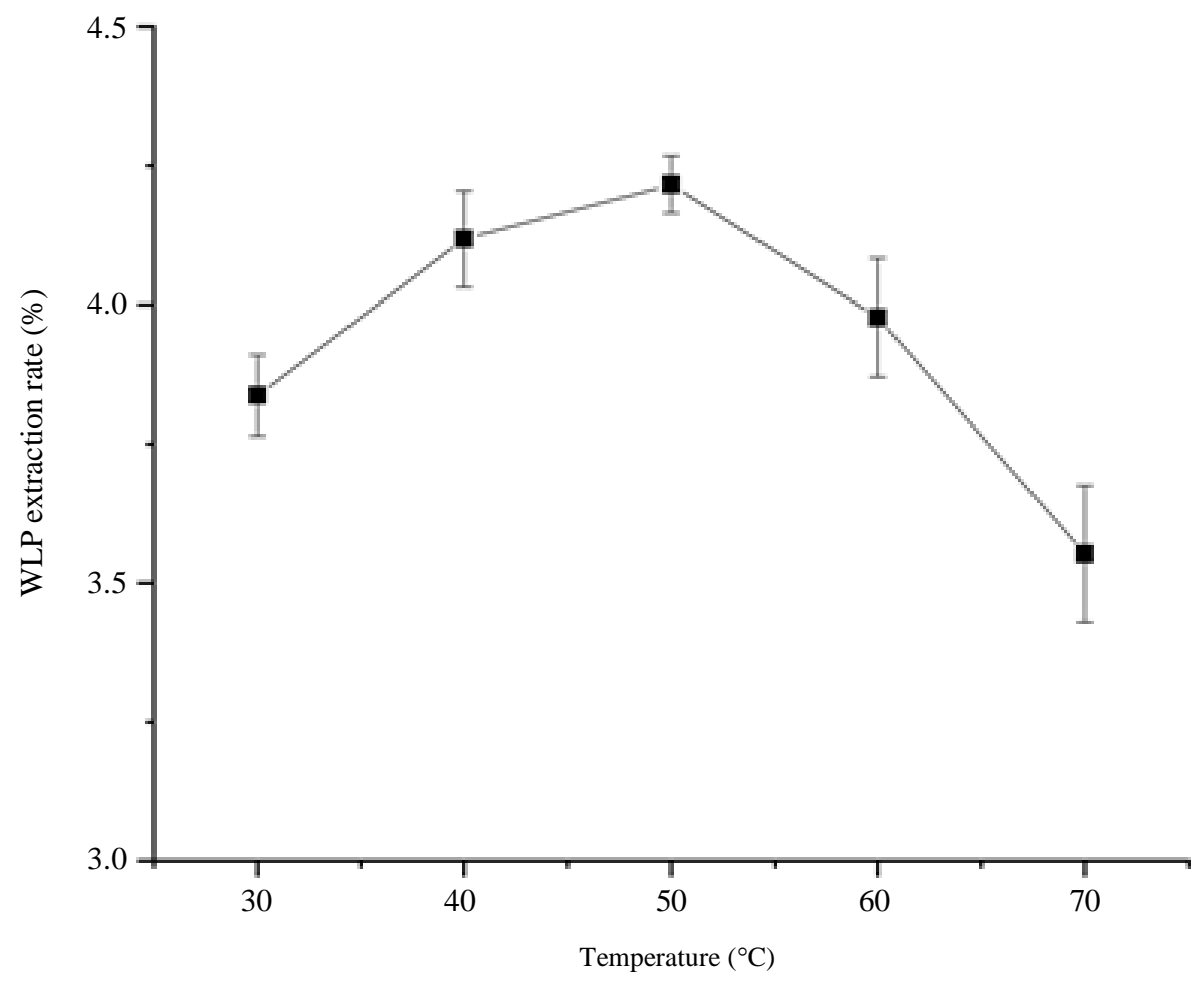

Fig. 5: Effects of enzymolysis temperature on extraction yield of WLP. Each value represents the mean \pm SD of three determinations

(A)
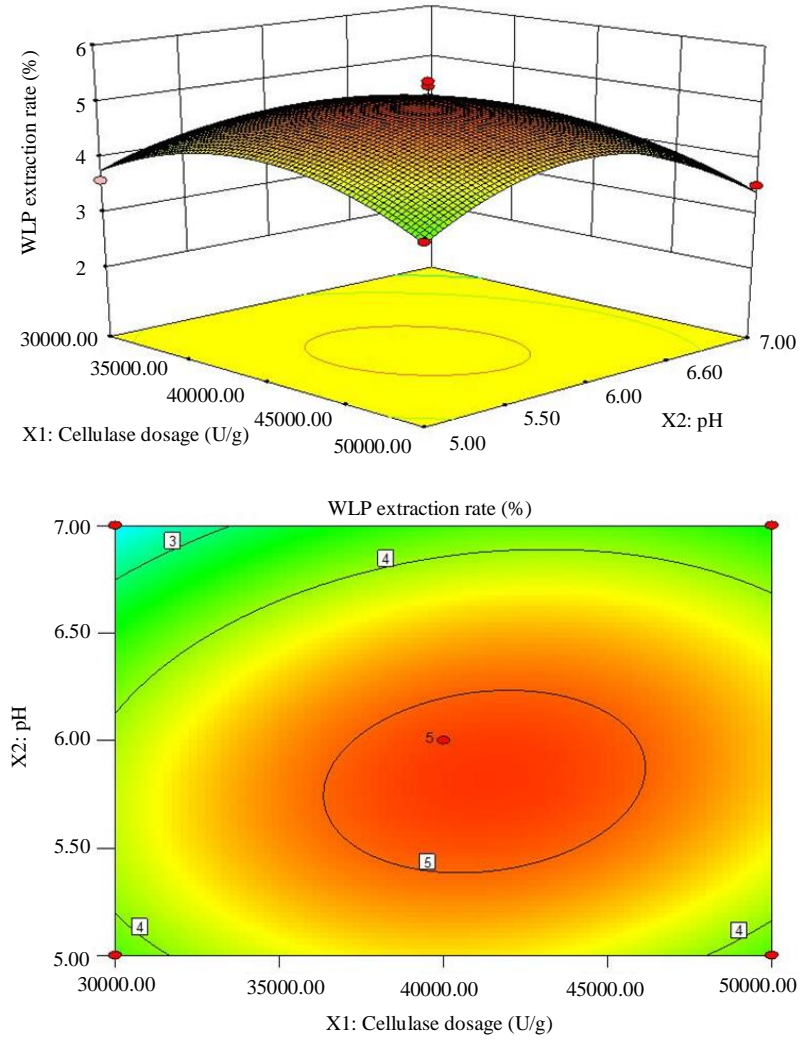

(B)
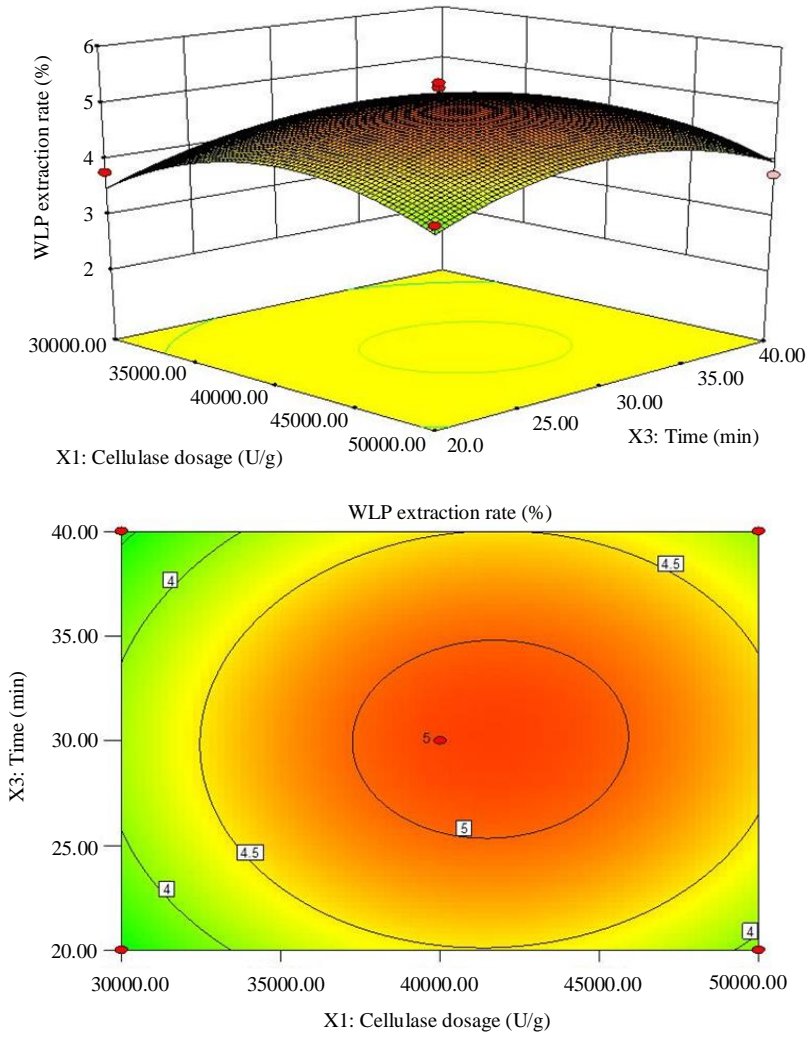
(C)
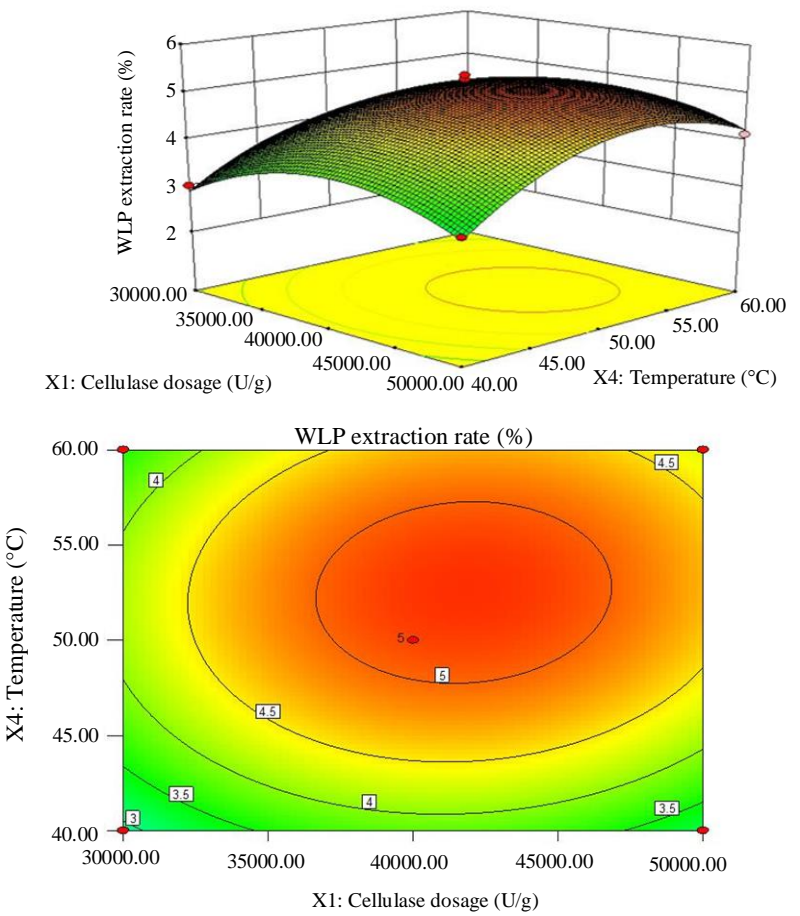

(E)
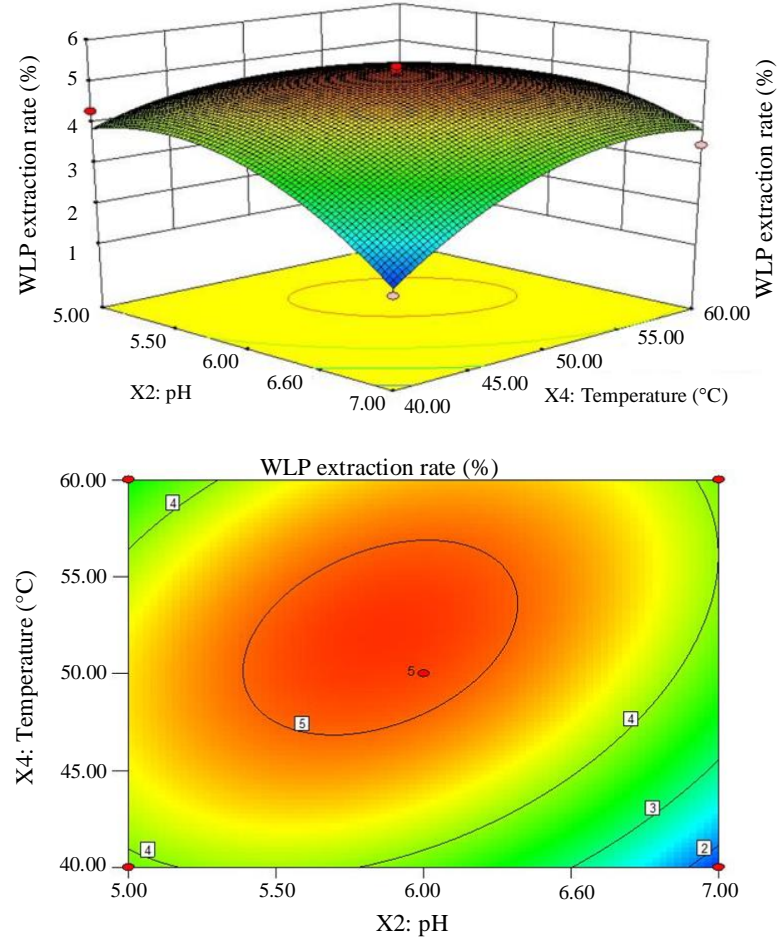

(D)
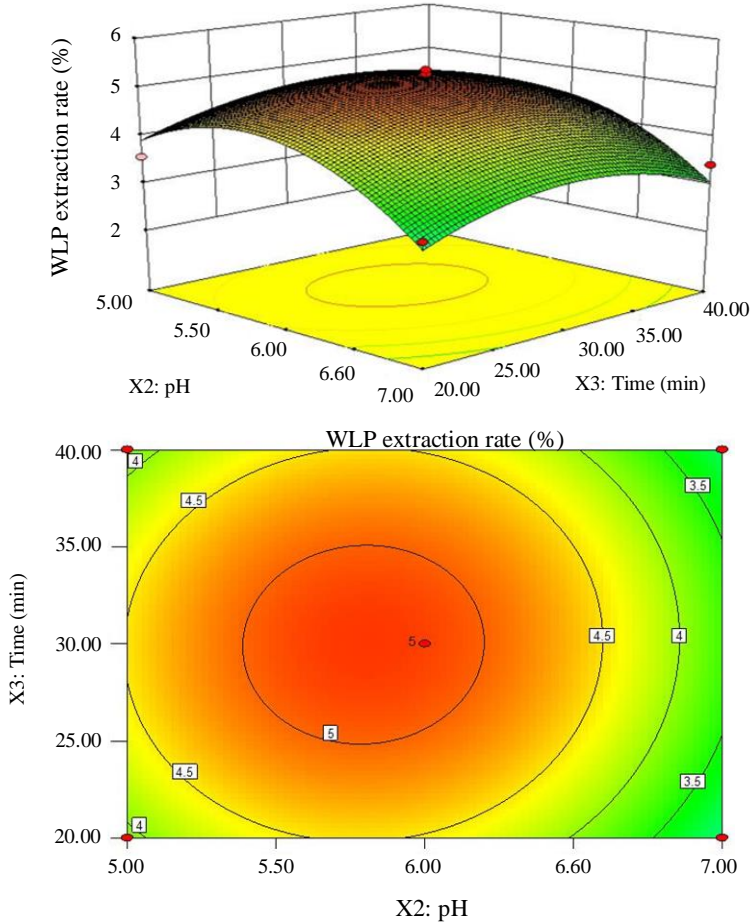

(F)
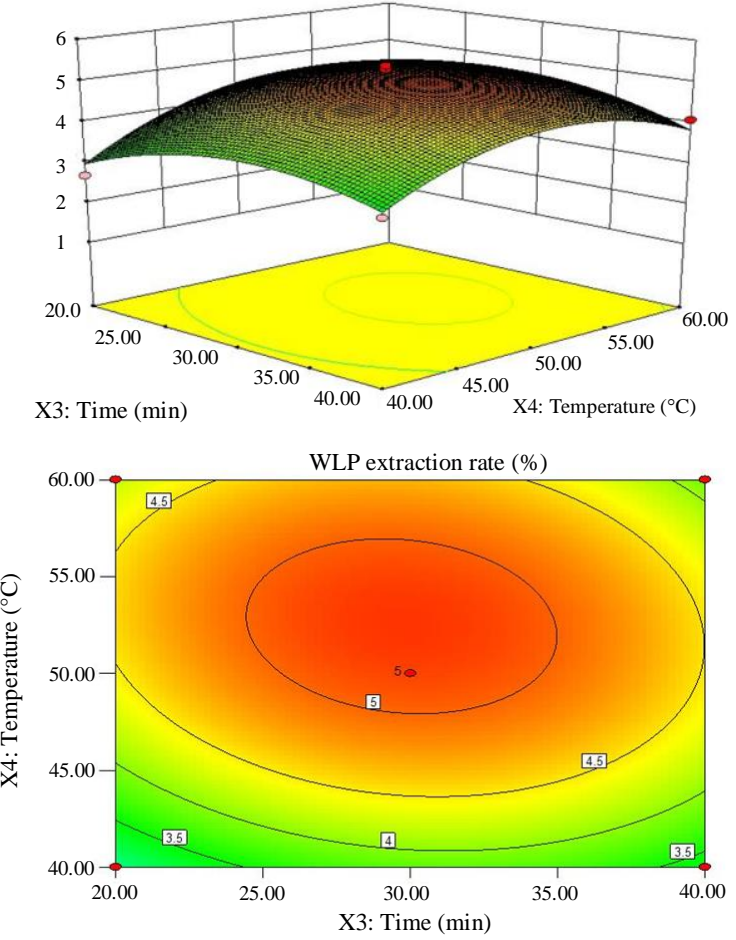

Fig. 6: Response surface plots (2D) and contour plots (3D) (A-F) showing the effect of different variables on the extraction yield of WLP. (A) The effect of cellulase dosage and enzymolysis $\mathrm{pH}$ on the WLP extraction rate; (B) The effect of cellulase dosage and enzymolysis time on the WLP extraction rate; (C) The effect of cellulase dosage and enzymolysis temperature on the WLP extraction rate; (D) The effect of enzymolysis $\mathrm{pH}$ and enzymolysis time on the WLP extraction rate; (E) The effect of enzymolysis $\mathrm{pH}$ and enzymolysis temperature on the WLP extraction rate; $(\mathrm{F})$ The effect of enzymolysis time and enzymolysis temperature on the WLP extraction rate 


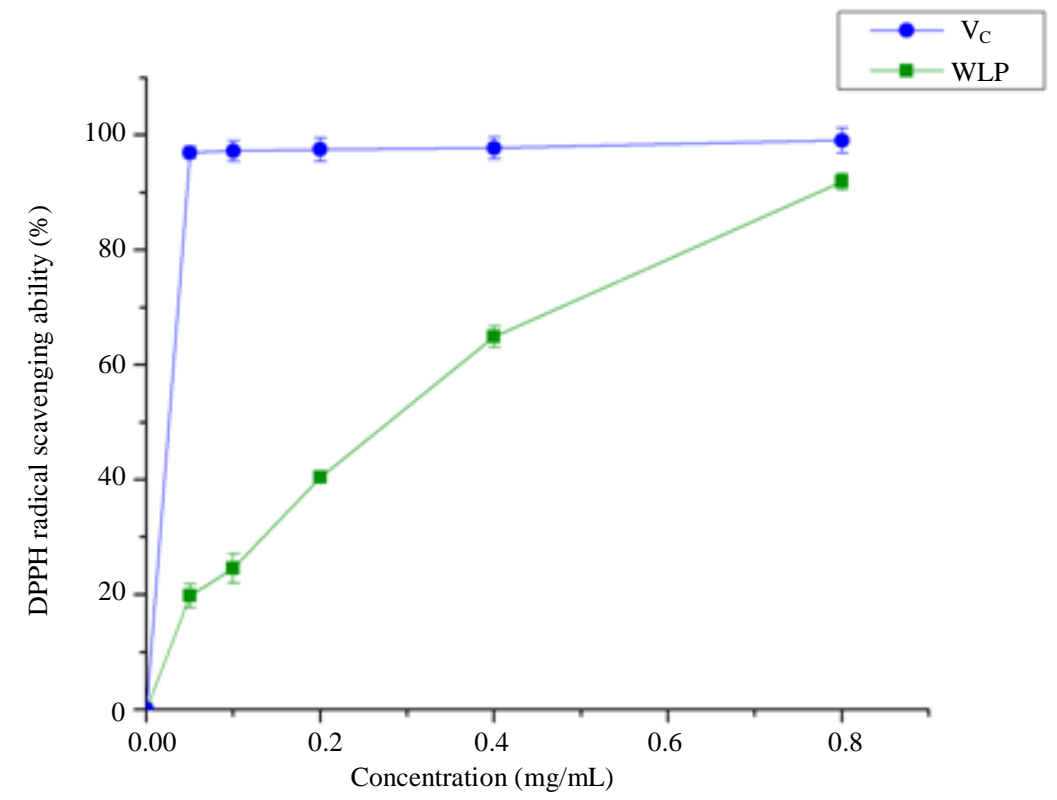

(a)

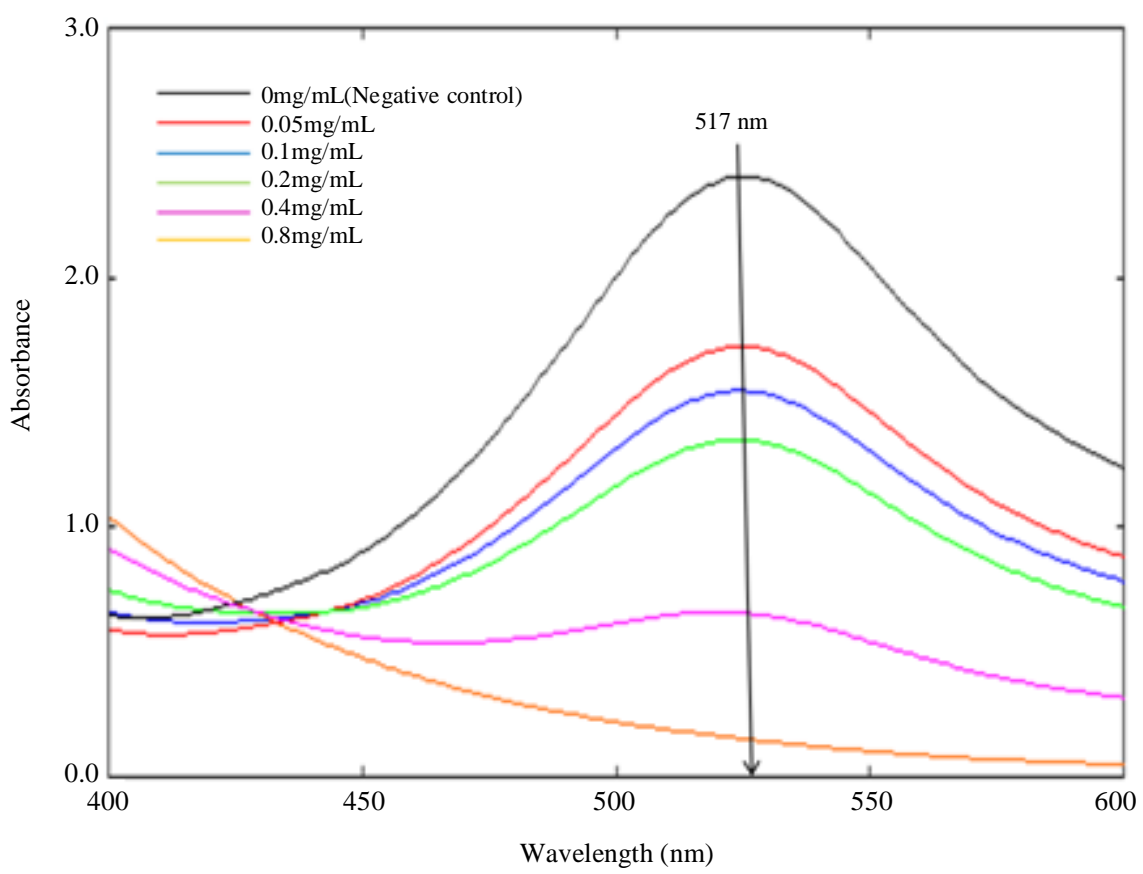

(b)

Fig. 7: Inhibition effects of WLP on DPPH free radicals. (a) Concentration-dependent inhibitions of WLP and $\mathrm{V}_{\mathrm{C}}$ (positive control) on DPPH free radicals. (b) Changes of UV absorbance spectra after the addition of different concentrations of WLP

The F-values and P-values of each model item are presented in Table 3 as a tool to test the significance of each coefficient. The F-test had a larger F-value and smaller $p$-value indicated that the more notable of relevant coefficient. Hence, the linear coefficients $\left(\mathrm{X}_{1}, \mathrm{X}_{2}, \mathrm{X}_{4}\right)$, cross coefficients $\left(\mathrm{X}_{2} \mathrm{X}_{4}\right)$ and quadratic coefficients $\left(\mathrm{X}_{1}^{2}, \mathrm{X}_{2}^{2}, \mathrm{X}_{3}^{2}, \mathrm{X}_{4}^{2}\right)$ all revealed a significant influence $(p<0.05)$ on the extraction yield of WLP. The enzymolysis $\mathrm{pH}\left(\mathrm{X}_{2}\right)$ and enzymolysis temperature $\left(\mathrm{X}_{4}\right)$ were the major parameter which influenced the WLP extraction yield followed by cellulase dosage $\left(\mathrm{X}_{1}\right)$ and enzymolysis time $\left(\mathrm{X}_{4}\right)$. However, coefficient of other terms was not significant $(\mathrm{p}>0.05)$. 


\section{Analysis of Response Surface Plot and Contour Plot}

In order to determine the interaction effect of various parameters on the response, triaxial section of the model was need to be generated, which were implemented by altering two parameters in experimental scopes and maintaining the other two variables at zero. As shown in Fig. 6, the interaction of the factors on the WLP extraction yield were inquired employing a three-dimensional response surface and two-dimensional outline plots.

As can be seen from Fig. 6A, the WLP extraction yield was increased in response to the increase of cellulase dosage $\left(\mathrm{X}_{1}\right)$ and enzymolysis $\mathrm{pH}\left(\mathrm{X}_{2}\right)$ when enzymolysis time and temperature were fixed at 0 levels. After acquiring the topmost WLP extraction yield relevanted to the $\mathrm{pH}-$ cellulase dosage reveal, undue $\mathrm{pH}$-cellulase dosage exposure would lead to a decline in the extraction rate.

Figure $6 \mathrm{~B}$ showed the interactions of cellulase dosage $\left(\mathrm{X}_{1}\right)$ and enzymolysis time $\left(\mathrm{X}_{3}\right)$ on the extraction ratio of WLP. Firstly, the output of WLP increased along with the increase of cellulase dose and enzymolysis time. After the WLP yield reached the maximum, the extraction yield of WLP did not increase even further.

Effect of enzymolysis temperature $\left(\mathrm{X}_{4}\right)$ on extraction rate was more obvious than that of the cellulase dosage $\left(\mathrm{X}_{1}\right)$, illustrating that the enzymolysis temperature generated a greater effect on WLP yield than cellulase dose (Fig. 6C). Fig. 6C showed that the WLP extraction yield increased firstly and then gradually declined with the increase of cellulase dosage and enzymolysis temperature, which was consistent with our results in Fig. 1A and 1E. Moreover, the maximum extraction yield of WLP was obtained when cellulase dosage and enzymolysis temperature were $41488.52 \mathrm{U} / \mathrm{g}$ and $52.07^{\circ} \mathrm{C}$, respectively.

Fig. 6D displayed the effects of $\mathrm{pH}\left(\mathrm{X}_{2}\right)$ and enzymolysis time $\left(\mathrm{X}_{3}\right)$ on the extraction yield of WLP. The extraction yield of WLP increased as $\mathrm{pH}$ ranged from 5 to 5.88 and enzymolysis time ranged from 20 to $29.74 \mathrm{~min}$, respectively and then decreased slightly.

The contour plots and 3-D response surface at different enzymolysis $\mathrm{pH}\left(\mathrm{X}_{2}\right)$ and enzymolysis temperature $\left(\mathrm{X}_{4}\right)$ as cellulase dose $\left(\mathrm{X}_{1}\right)$ and enzymolysis time $\left(\mathrm{X}_{3}\right)$ were fixed at 0 levels are shown in Fig. 6E. The highest WLP extraction yield was obtained when the $\mathrm{pH}$ and the enzymolysis temperature was 5.88 and $52.07^{\circ} \mathrm{C}$, respectively. With further increase of $\mathrm{pH}$ and temperature, the declined trend of the extraction yield of WLP was displayed.

In Fig. 6F, the production gained along with the increase of enzymolysis time $\left(\mathrm{X}_{3}\right)$ and temperature $\left(X_{4}\right)$. Nevertheless, extended time and higher temperatures slightly reduced the extraction yield of WLP within the test zone.

\section{Verification of Predictive Model}

Based on the single factor experiment and 3D response surface, optimum extraction conditions for
WLP were as follows: cellulase dosage of $41488.52 \mathrm{U} / \mathrm{g}$, enzymolysis $\mathrm{pH}$ of 5.88, enzymolysis time of $29.74 \mathrm{~min}$ and enzymolysis temperature of $52.07^{\circ} \mathrm{C}$. Under these optimum extraction conditions, the maximum predicted value of extraction yield of WLP was $5.21 \%$.

To verify the feasibility and reliability of the model, triplicate confirmatory experiments were executed under conditions including cellulase dosage of $41000 \mathrm{U} / \mathrm{g}$, enzymolysis $\mathrm{pH}$ of 5.8 , enzymolysis time of $30 \mathrm{~min}$ and enzymolysis temperature of $52^{\circ} \mathrm{C}$ and the extraction yield of WLP was $5.24 \%$, which was closely approached the predicted value. Base on the above, the model used in this study was adequate for assessing the extraction field of WLP.

\section{DPPH free Radical Scavenging Activity}

DPPH free radical is a stable lipophilic free radical with a maximum absorption at $517 \mathrm{~nm}$. Thereby, it has been widely used to investigate the antioxidant property of natural compounds in vitro (Huang et al., 2016; Mzoughi et al., 2018). The DPPH radical scavenging capacities of WLP at different concentrations (0.05-0.8 $\mathrm{mg} / \mathrm{mL}$ ) were studied with ascorbic acid as a reference. As can be seen in Fig. 7A and B, both WLP and ascorbic acid exhibited obvious scavenging effect on DPPH radical in a dose-dependent manner at a comparatively lower concentration. At the concentration of $0.8 \mathrm{mg} / \mathrm{mL}$, the scavenging activities of WLP and ascorbic acid were $81.93 \%$ and $98.06 \%$, respectively. Moreover, the variational tendency in absorption bands at $517 \mathrm{~nm}$ from the ultraviolet-visible (UV-vis) spectral scanning confirmed the DPPH radical scavenging ability.

Studies showed that polysaccharide from olive leaves also had good scavenging ability to DPPH free radicals (Khemakhem et al., 2018).

\section{ABTS Free Radical Scavenging Activity}

ABTS is extensively usedto evaluate the scavenging power of natural products extracted from various plants (Meng et al., 2017). Therefore, ABTS free radical was also applied to assess the antioxidant property of WLP in our examination. The antioxidant ability of all samples on ABTS free radicals were displayed in Fig. 8A and B. Obviously, the outcomes declared the WLP behaved strongly ABTS scavenging capacities at all tested concentrations and the ABTS scavenging ability of WLP strengthened drastically with the increase of WLP dosage. Additionally, WLP exhibited the highest ABTS scavenging ability of $94.8 \%$ at a concentration of 0.8 $\mathrm{mg} / \mathrm{mL}$, which was close to the highest ABTS scavenging ability of ascorbic acid (99.42\%). Previous studies have reported that the ABTS scavenging activity of gracilaria rubra crude polysaccharides was $55.34 \%$ at the concentration of $2.5 \mathrm{mg} / \mathrm{mL}$ and a polysaccharide named DJP-2 from diaphragma juglandis fructus demonstrated ABTS radical scavenging function of $78.31 \%$ at a concentration of $4 \mathrm{mg} / \mathrm{mL}$ (Di et al., 2017; Meng et al., 2017). 


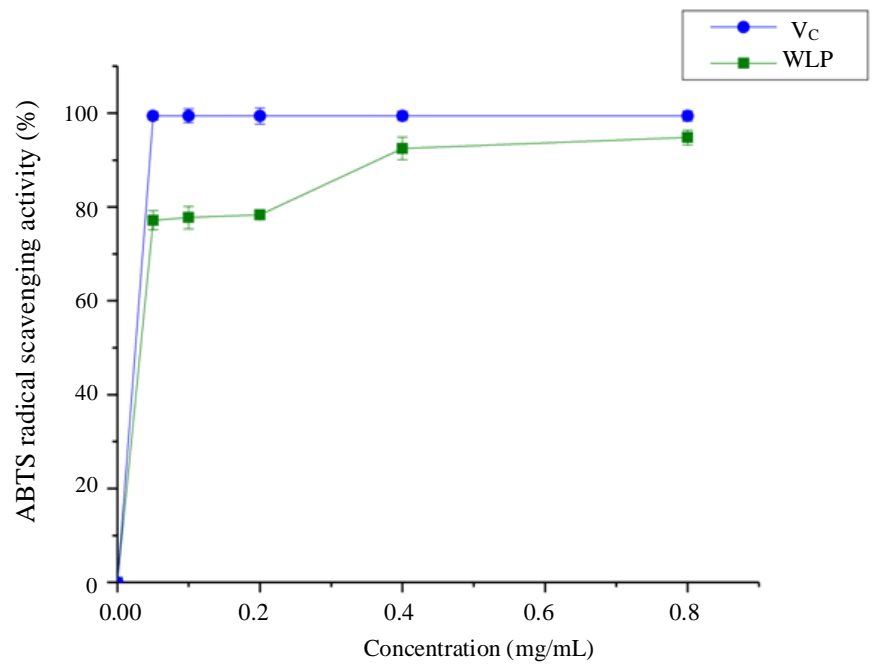

(a)

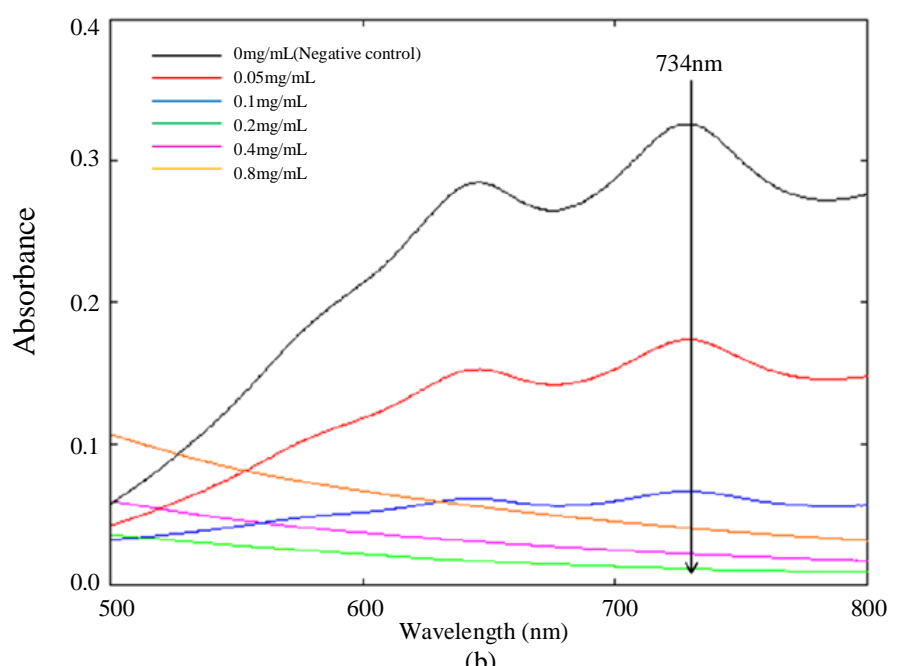

(b)

Fig. 8: Inhibition effects of WLP on ABTS free radicals. (a) Concentration-dependent inhibitions of WLP and $V_{C}$ (positive control) on ABTS free radicals. (b) Changes of UV absorbance spectra after the addition of different concentrations of WLP

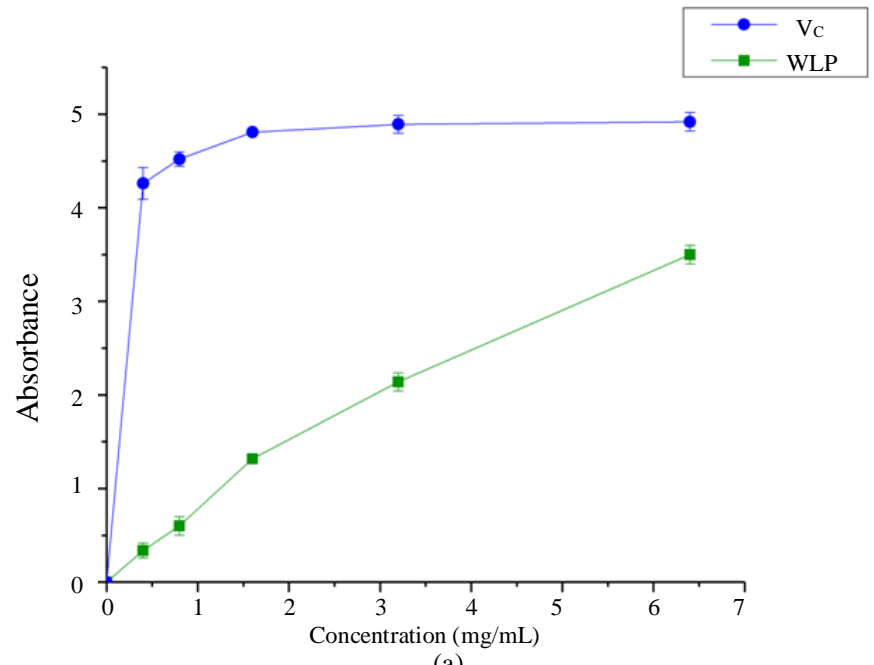

(a) 


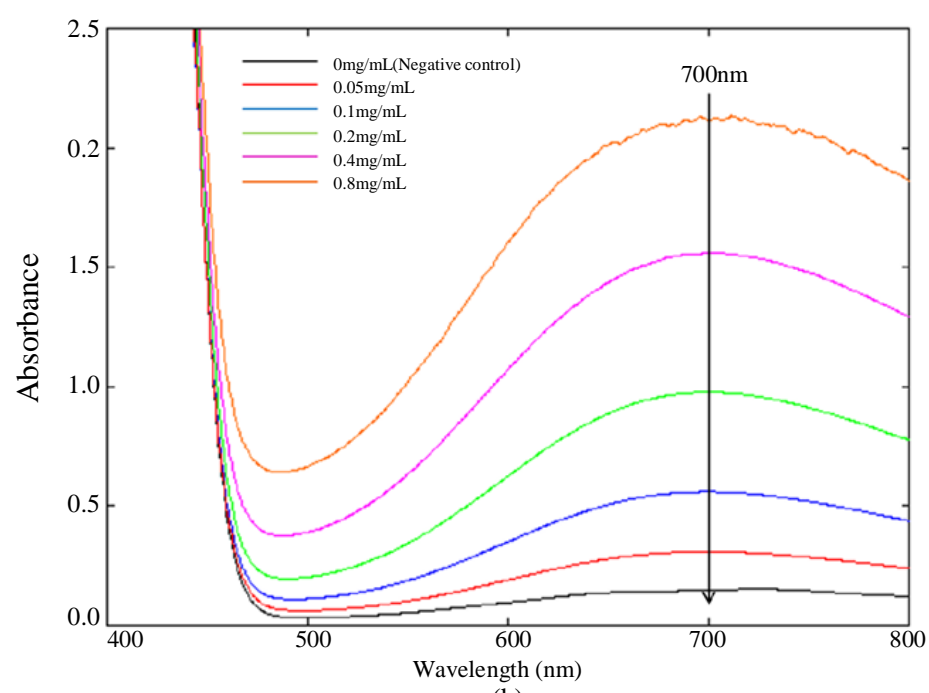

(b)

Fig. 9: Reducing power of WLP. (a) Concentration-dependent reducing power of WLP and $\mathrm{V}_{\mathrm{C}}$ (positive control). (b) Changes of UV absorbance spectra after the addition of different concentrations of WLP

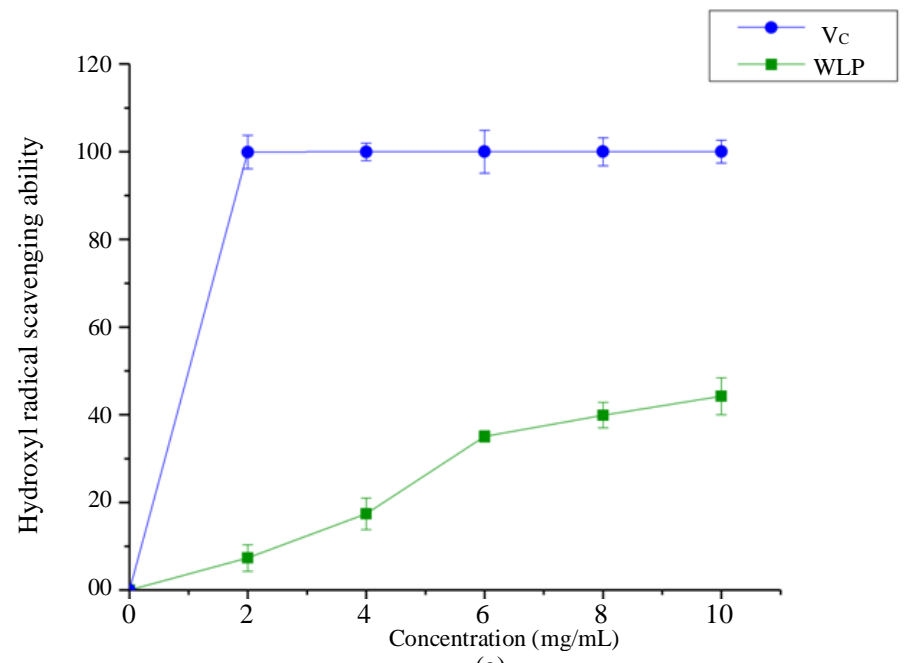

(a)

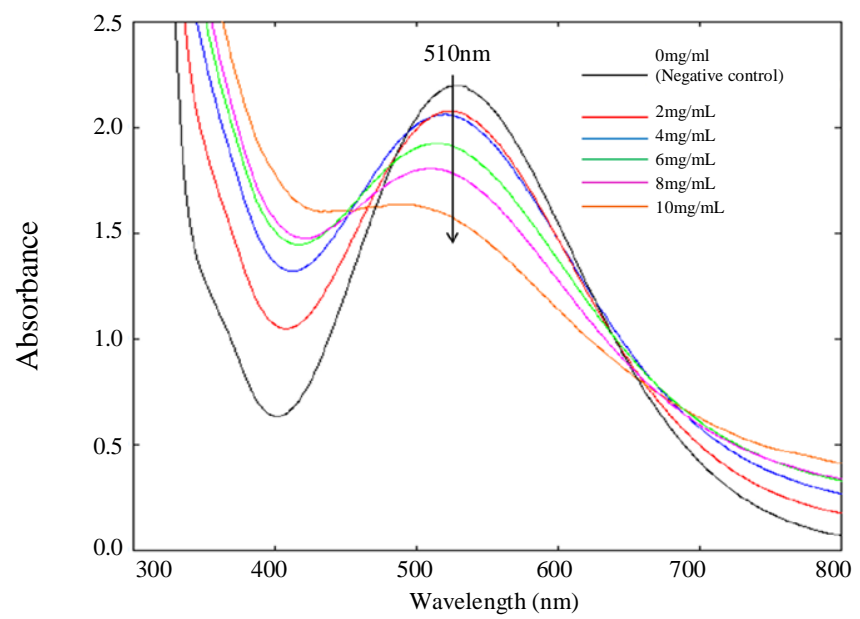

(b)

Fig. 10: Inhibition effects of WLP on hydroxyl free radicals. (a) Concentration-dependent inhibitions of WLP and $V_{C}$ (positive control) on hydroxyl free radicals. (b) Changes of UV absorbance spectra after the addition of different concentrations of WLP 


\section{FRAP Assay}

It has been reported that the antioxidant activity of active substance is directly related to its reducing power (Khemakhem et al., 2018). Ferrous ion is considered to be an effective food pro-oxidant because of its role in promoting lipid peroxidation (Huang et al., 2016). Therefore, the FRAP test using the principle of ferrous ion and TPTZ (tripyridyl-triazine) to generate bluepurple complex is widely used in analyzing antioxidant capacity of natural active components and is determined by measuring the absorbance of reaction blend at 700 nm. The higher absorbance value manifested stronger reducing power of natural antioxidants (Yin et al., 2018).

The FRAP of WLP was determined in this study and the results were shown in Fig. 9A and B. WLP displayed significant FRAP activities in a concentration-dependent pattern within the test concentration range (0.4-6.4 $\mathrm{mg} / \mathrm{mL}$ ). Nevertheless, the FRAP of WLP was weaker than that of ascorbic acid. According to the previous reports, polysaccharides extracted from Lentinus edodes and Euryale ferox salisb. exhibited obvious FRAP activities (Wu et al., 2014; Yin et al., 2018). The consequences disclosed that WLP could act as an electron donor in radical chain reactions, react with free radicals to transform them into further stabilized end-product.

\section{Hydroxyl Radical Scavenging Activity}

Hydroxyl radical is the most oxidizing radical and can non-specifically oxygenate different types of biomolecules in the tissue cells which result in cytotoxicity, carcinogenesis and other diseases ( $\mathrm{Li}$ and Shah, 2014; Xu et al., 2012). Hence, the hydroxyl radical eliminating power is also one of the crucial indications of antioxidant abilities. As illustrated in Fig. 10A and B, WLP exhibited a reversely limited scavenging activities on hydroxyl radicals compared with ascorbic acid within a concentration range of 2 to $10 \mathrm{mg} / \mathrm{mL}$. At the concentration of $10 \mathrm{mg} / \mathrm{mL}$, the scavenging effects of WLP and ascorbic acid on hydroxyl free radical were $44.23 \%$ and $100 \%$, respectively, which was similar to the interpretations of (He et al., 2011; Xu et al., 2012).

\section{Conclusion}

In this study, the crude polysaccharide was successfully extracted from walnut leaves using optimization of cellulase assisted water extraction process. The antioxidant activities of WLP in vitro were determined by four indexes including DPPH, ABTS and hydroxyl radical scavenging abilities as well as reducing power. The results indicated that WLP exhibited a higher free-radical scavenging ability in a dose-dependent manner. Based on the above, polysaccharide acquired from walnut leaves is a potential natural antioxidant agent, which is expected to be used in functional food or medicine industry. What's more important, future work will focus on exploring the mechanism of its functional activity.

\section{Acknowledgement}

This work was supported by SDUT and Zibo City Integration Development Project (2017ZBXC004) and Shandong Provincial Natural Science Foundation, China (No. ZR2014CQ002). Therefore, we are grateful for the funding and support of this research

\section{Funding Information}

This work was supported by SDUT \& Zibo City Integration Development Project (2017ZBXC004) and Shandong Provincial Natural Science Foundation, China (No. ZR2014CQ002).

\section{Author's Contributions}

Shuqing Yang: Participated in the whole experiment process and also contributed to the interpretation of the results and manuscript preparation.

Haifang Xiao: Contributed to the study design, the interpretation of the results and manuscript preparation.

Shuyan Yu: Participated in part of the experimental design.

Zhike Xie: Participated in part of the experimental design.

Shaoxuan Yu: Ameliorated the manuscript.

Wanting Sun: Contributed to the experiment of polysaccharide extraction.

Yuanda Song: Contributed to the guidance of experimental design and ameliorated the manuscript.

\section{Ethics}

This article is original and contains unpublished material. The corresponding author confirms that all of the other authors have read and approved the manuscript and no ethical issues involved.

\section{References}

Almeida, I.F., E. Fernandes, J.L.F.C. Lima, P.C. Costa and Fernanda M. Bahia, 2008. Walnut (Juglans regia) leaf extracts are strong scavengers of prooxidant reactive species. Food Chem., 106: 1014-1020. DOI: 10.1016/j.foodchem.2007.07.017

Caicai, K., H. Limin, Z. Liming, Z. Zhiqiang and Y. Yongwu, 2018. Isolation, purification and antioxidant activity of polysaccharides from the leaves of maca (Lepidium Meyenii). Int. J. Biol. Macromol., 107: 2611-2619.

DOI: 10.1016/j.ijbiomac.2017.10.139 
Carvalho, M., P.J. Ferreira, V.S. Mendes, R. Silva and J.A. Pereira et al., 2010. Human cancer cell antiproliferative and antioxidant activities of Juglans regia L. Food Chem. Toxicol., 48: 441-447. DOI: 10.1016/j.fct.2009.10.043

Chen, C., B. Zhang, Q. Huang, X. Fu and R.H. Liu, 2017. Microwave-assisted extraction of polysaccharides from Moringa oleifera Lam. leaves: Characterization and hypoglycemic activity. Ind. Crop. Prod., 100: 1-11. DOI: 10.1016/j.indcrop.2017.01.042

Di, T., G. Chen, Y. Sun, S. Ou, X. Zeng and H. Ye, 2017. Antioxidant and immunostimulating activities in vitro of sulfated polysaccharides isolated from Gracilaria rubra. J. Funct. Foods, 28: 64-75. DOI: $10.1016 /$ j.jff.2016.11.005

Forino, M., P. Stiuso, S. Lama, P. Ciminiello and G.C. Tenore et al., 2016. Bioassay-guided identification of the antihyperglycaemic constituents of walnut (Juglans regia) leaves. J. Funct. Foods, 26: 731-738. DOI: $10.1016 /$ j.jff.2016.08.053

Gao, J., T. Zhang, Z.Y. Jin, X.M. Xu and J.H. Wang et al., 2015. Structural characterisation, physicochemical properties and antioxidant activity of polysaccharide from Lilium lancifolium Thunb. Food Chem., 169: 430-438.

DOI: 10.1016/j.foodchem.2014.08.016

He, L., P. Ji, X. Gong, W. Li, J. Cheng, H. Qian and X. Song, 2011. Physico-chemical characterization, antioxidant and anticancer activities in vitro of a novel polysaccharide from Melia toosendan Sieb. Et Zucc fruit. Int. J. Biol. Macromol., 49: 422-427. DOI: 10.1016/j.ijbiomac.2011.05.028

Hu, J., X. Jia, X. Fang, P. Li, C. He and M. Chen, 2016. Ultrasonic extraction, antioxidant and anticancer activities of novel polysaccharides from Chuanxiong rhizome. Int. J. Biol. Macromol., 85: 277-284. DOI: $10.1016 /$ j.ijbiomac.2015.12.046

Huang, C.Y., S.J. Wu, W.N. Yang, A.W. Kuan and C.Y. Chen, 2016. Antioxidant activities of crude extracts of fucoidan extracted from Sargassum glaucescens by a compressional-puffing-hydrothermal extraction process. Food Chem., 197: 1121-1129.

DOI: 10.1016/j.foodchem.2015.11.100

Jeddou, K.B., F. Chaari, S. Maktouf, O. Nouri-Ellouz and C.B. Helbert et al., 2016. Structural, functional and antioxidant properties of water-soluble polysaccharides from potatoes peels. Food Chem., 205: 97-105. DOI: 10.1016/j.foodchem.2016.02.108

Khemakhem, I., O. Abdelhedi, I. Trigui, M.A. Ayadi and M. Bouaziz, 2018. Structural, antioxidant and antibacterial activities of polysaccharides extracted from olive leaves. Int. J. Biol. Macromol., 106: 425432. DOI: 10.1016/j.ijbiomac.2017.08.037
Kurd, F. and V. Samavati, 2015. Water soluble polysaccharides from Spirulina platensis: Extraction and in vitro anti-cancer activity. Int. J. Biol. Macromol., 74: 498-506.

DOI: $10.1016 /$ j.ijbiomac.2015.01.005

Lai, F., Q. Wen, L. Li, H. Wu and X. Li, 2010. Antioxidant activities of water-soluble polysaccharide extracted from mung bean (Vigna radiata L.) hull with ultrasonic assisted treatment. Carbohydr. Polym., 81: 323-329. DOI: 10.1016/j.carbpol.2010.02.011

Li, S. and N.P. Shah, 2014. Antioxidant and antibacterial activities of sulphated polysaccharides from pleurotus eryngii and Streptococcus thermophilus ASCC 1275. Food Chem., 165: 262-270.

DOI: 10.1016/j.foodchem.2014.05.110

Liu, Q., X. Ge, L. Chen, D. Cheng and Z. Yun et al., 2018. Purification and analysis of the composition and antioxidant activity of polysaccharides from Helicteres angustifolia L. Int. J. Biol. Macromol., 107: 2262-2268. DOI: 10.1016/j.ijbiomac.2017.10.095

Mazarei, F., H. Jooyandeh, M. Noshad and M. Hojjati, 2017. Polysaccharide of caper (Capparis spinosa L.) Leaf: Extraction optimization, antioxidant potential and antimicrobial activity. Int. J. Biol. Macromol., 95: 224-231. DOI: 10.1016/j.ijbiomac.2016.11.049

Meng, Q., Y. Li, T. Xiao, L. Zhang and D. Xu, 2017. Antioxidant and antibacterial activities of polysaccharides isolated and purified from Diaphragma juglandis fructus. Int. J. Biol. Macromol., 105: 431-437. DOI: 10.1016/j.ijbiomac.2017.07.062

Mkadmini Hammi, K., M. Hammami, C. Rihouey, D. Le Cerf and R. Ksouri et al., 2016. Optimization extraction of polysaccharide from Tunisian Zizyphus lotus fruit by response surface methodology: Composition and antioxidant activity. Food Chem., 212: 476-484. DOI: 10.1016/j.foodchem.2016.06.004

Mollica, A., G. Zengin, M. Locatelli, A. Stefanucci and G. Macedonio et al., 2017. An assessment of the nutraceutical potential of Juglans regia $L$. leaf powder in diabetic rats. Food Chem. Toxicol, 107: 554-564. DOI: 10.1016/j.fct.2017.03.056

Mzoughi, Z., A. Abdelhamid, C. Rihouey, D. Le Cerf and A. Bouraoui et al., 2018. Optimized extraction of pectin-like polysaccharide from Suaeda fruticosa leaves: Char provide good visual imperceptibility and ensure acterization, antioxidant, antiinflammatory and analgesic activities. Carbohydr Polym., 185: 127-137.

DOI: 10.1016/j.carbpol.2018.01.022

Mzoughi, Z., M.A. Chaouch, K.M. Hammi, J. Hafsa and D. Le Cerf et al., 2018. Optimization of antioxidant and antiglycated activities of polysaccharides from Arthrocnemum indicum leaves. Int. J. Biol. Macromol., 113: 774-782.

DOI: 10.1016/j.ijbiomac.2018.03.008 
Palanisamy, S., M. Vinosha, T. Marudhupandi, P. Rajasekar and N.M. Prabhu, 2017. Isolation of fucoidan from Sargassum polycystum brown algae: Structural characterization, in vitro antioxidant and anticancer activity. Int. J. Biol. Macromol., 102: 405-a412.

DOI: $10.1016 /$ j.ijbiomac.2017.03.182

Pereira, J.A., I. Oliveira, A. Sousa, P. Valentao and P.B. Andrade et al., 2007. Walnut (Juglans regia L.) leaves: Phenolic compounds, antibacterial activity and antioxidant potential of different cultivars. Food Chem. Toxicol, 45: 2287-2295.

DOI: $10.1016 /$ j.fct.2007.06.004

Shen, S., Z. Xu, S. Feng, H. Wang and J. Liu et al., 2018. Structural elucidation and antiaging activity of polysaccharide from Paris polyphylla leaves. Int. J. Biol. Macromol., 107: 1613-1619.

DOI: 10.1016/j.ijbiomac.2017.10.026

Wang, C.Y., T.C. Wu, S.L. Hsieh, Y.H. Tsai and C.W. Yeh et al., 2015. Antioxidant activity and growth inhibition of human colon cancer cells by crude and purified fucoidan preparations extracted from Sargassum cristaefolium. J. Food Drug. Anal, 23: 766-777. DOI: 10.1016/j.jfda.2015.07.002

Wu, C., X. Wang, H. Wang, B. Shen and X. He et al., 2014. Extraction optimization, isolation, preliminary structural characterization and antioxidant activities of the cell wall polysaccharides in the petioles and pedicels of Chinese herbal medicine Qian (Euryale ferox Salisb.). Int. J. Biol. Macromol., 64: 458-467. DOI: 10.1016/j.ijbiomac.2013.12.025

Xie, J.H., X. Liu, M.Y. Shen, S.P. Nie and H. Zhang et al., 2013. Purification, physicochemical characterisation and anticancer activity of a polysaccharide from Cyclocarya paliurus leaves. Food Chem., 136: 1453-1460.

DOI: 10.1016/j.foodchem.2012.09.078

$\mathrm{Xu}, \mathrm{R} ., \mathrm{H} . \mathrm{Ye}, \mathrm{Y}$. Sun, Y. Tu and X. Zeng, 2012. Preparation, preliminary characterization, antioxidant, hepatoprotective and antitumor activities of polysaccharides from the flower of tea plant (Camellia sinensis). Food Chem. Toxicol, 50: 2473-2480. DOI: 10.1016/j.fct.2011.10.047
Xu, Y., F. Cai, Z. Yu, L. Zhang and X. Li et al., 2016. Optimisation of pressurised water extraction of polysaccharides from blackcurrant and its antioxidant activity. Food Chem., 194: 650-658. DOI: 10.1016/j.foodchem.2015.08.061

Yang, S., Y. Li, D. Jia, K. Yao and W. Liu, 2017. The synergy of Box-Behnken designs on the optimization of polysaccharide extraction from mulberry leaves. Ind. Crop. Prod., 99: 70-78.

DOI: $10.1016 /$ j.indcrop.2017.01.024

Yin, C., X. Fan, Z. Fan, D. Shi and H. Gao, 2018. Optimization of enzymes-microwave-ultrasound assisted extraction of Lentinus edodes polysaccharides and determination of its antioxidant activity. Int. J. Biol. Macromol., 111: 446-454. DOI: 10.1016/j.ijbiomac.2018.01.007

Yu, Y., M. Shen, Q. Song and J. Xie, 2018. Biological activities and pharmaceutical applications of polysaccharide from natural resources: A review. Carbohydr. Polym., 183: 91-101. DOI: 10.1016/j.carbpol.2017.12.009

Yun, L., D. Li, L. Yang and M. Zhang, 2019. Hot water extraction and artificial simulated gastrointestinal digestion of wheat germ polysaccharide. Int. J. Biol. Macromol., 123: 174-181.

DOI: 10.1016/j.ijbiomac.2018.11.111

Zhao, Y., W. Hu, H. Zhang, C. Ding and Y. Huang et al., 2019. Antioxidant and immunomodulatory activities of polysaccharides from the rhizome of Dryopteris crassirhizoma Nakai. Int. J. Biol. Macromol., 130: 238-244.

DOI: 10.1016/j.ijbiomac.2019.02.119

Zhao, Y.M., J. Wang, Z.G. Wu, J.M. Yang and W. Li et al., 2016. Extraction, purification and antiproliferative activities of polysaccharides from Lentinus edodes. Int. J. Biol. Macromol., 93: 136-144. DOI: 10.1016/j.ijbiomac.2016.05.100

Zhu, Y., Q. Li, G. Mao, Y. Zou and W. Feng et al., 2014. Optimization of enzyme-assisted extraction and characterization of polysaccharides from Hericium erinaceus. Carbohydr. Polym., 101: 606-613. DOI: 10.1016/j.carbpol.2013.09.099 